\title{
Carbon monoxide fermentation to ethanol by Clostridium autoethanogenum in a bioreactor with no accumulation of acetic acid
}

\author{
Haris Nalakath Abubackar, María C. Veiga, Christian Kennes' \\ Chemical Engineering Laboratory, Faculty of Sciences, University of La Coruña, Rúa da Fraga 10, 15008 \\ La Coruña, Spain
}

\section{Bioresource Technology}

Volume 186, June 2015, Pages 122-127

Received 19 January 2015, Revised 25 February 2015, Accepted 26 February 2015, Available online 13 March 2015

CrossRef DOI Link to Publisher-Maintained Copy: http://dx.doi.org/10.1016/j.biortech.2015.02.113

\section{Highlights}

- The presence of tungsten improved ethanol production from CO fermentation.

- Selenium and vitamins addition did not improve the ethanol/acetic acid ratio.

- The 2,3-butanediol/acetic acid ratio increased with the addition of tungsten.

- The addition of tungsten, at low pH, resulted in no accumulation of acetic acid.

\begin{abstract}
Fermentation of $\mathrm{CO}$ or syngas offers an attractive route to produce bioethanol. However, during the bioconversion, one of the challenges to overcome is to reduce the production of acetic acid in order to minimize recovery costs. Different experiments were done with Clostridium autoethanogenum. With the addition of $0.75 \mu \mathrm{M}$ tungsten, ethanol production from carbon monoxide increased by about $128 \%$ compared to the control, without such addition, in batch mode. In bioreactors with continuous carbon monoxide supply, the maximum biomass concentration reached at $\mathrm{pH} 6.0$ was $109 \%$ higher than the maximum achieved at $\mathrm{pH} 4.75$ but, interestingly, at $\mathrm{pH} 4.75$, no acetic acid was produced and the ethanol titer reached a maximum of $867 \mathrm{mg} / \mathrm{L}$ with minor amounts of 2,3-butanediol ( $46 \mathrm{mg} / \mathrm{L})$. At the higher $\mathrm{pH}$ studied ( $\mathrm{pH}$ 6.0) in the continuous gas-fed bioreactor, almost equal amounts of ethanol and acetic acid were formed, reaching $907.72 \mathrm{mg} / \mathrm{L}$ and $910.69 \mathrm{mg} / \mathrm{L}$ respectively.
\end{abstract}




\section{Keywords}

- Bioethanol;

- Butanediol;

- Selenium;

- Syngas;

- Tungsten

\section{Introduction}

In recent years, growing interest has been found in the use of bio-based fuels as a result of the gradual depletion of global oil reserves and consensus on climate change. By 2020, it will be mandatory for all the Member States (MS) of the EU to reach their assigned targets in terms of energy and to achieve a $20 \%$ share of renewable energy (van Groenestijn et al., 2013). Moreover, the use of $10 \%$ renewable energy in transportation will be mandatory by then for all MS (Latif et al., 2014). Bioethanol was one of the biofuels which accounted for $28 \%$ of the overall biofuels used in the road transport in the EU in 2012. EU bioethanol production was forecasted to reach 5.38 billion liters in 2014 (Flach et al., 2013). Grains such as wheat, corn, barley and rye are currently the prominent feedstocks for bioethanol production in the EU. However, this leads to food-fuel competition. Hence, one way to overcome this situation is to utilize highly available lignocellulosic biomass or even waste as raw material for bioethanol production. However, the conventional way of bioconversion of lignocellulosic biomass to bioethanol is a somewhat complex process (Balat and Balat, 2009). An alternative and promising new generation bioethanol production process is through gasification of biomass in order to generate syngas or producer gas, composed mainly of $\mathrm{CO}, \mathrm{CO}_{2}$ and $\mathrm{H}_{2}$. It is later introduced into a fermentor that is inoculated with anaerobic bacteria, mainly belonging to genera such as Clostridium, under specific process conditions (Abubackar et al., 2011a,Bengelsdorf et al., 2013 and Mohammadi et al., 2011). The biocatalysts use these $\mathrm{C}_{1}$ compounds as sole carbon source, following the reductive acetyl-CoA pathway, leading to the production of ethanol and acetic acid. Trace amounts of 2,3-butanediol, butanol, lactic acid are also reportedly being produced during the fermentation (Bengelsdorf et al., 2013). Recently, some studies were published on syngas fermentation with genetically engineered biocatalysts as well ( Ueki et al., 2014 and Xie et al., 2015). On the other hand, studies are still ongoing with wild type strains of bacteria to improve the ethanol productivity by manipulating several parameters, such as the medium composition and/or fermentor operating conditions (Abubackar et al., 2012 and Kundiyana et al., 2011).

The reductive acetyl-CoA pathway, also known as the Wood-Ljungdahl (WL) pathway, comprises an Eastern or methyl branch and a Western or carbonyl branch that use $\mathrm{CO}$ and/or $\mathrm{CO}_{2}$ as the substrate for the synthesis of acetyl-CoA, the intermediate that serves as precursor for the formation of biomass and metabolites such as ethanol and acetic acid. The proteins that are involved in the WL pathway, require cofactors such as $\mathrm{H}_{4}$-folate, cobalamin, metal ions or FeS-clusters. For example, Corrinoid FeS proteins contain both cobalamin with a central cobalt atom and an FeS cluster. Carbon monoxide dehydrogenase $(\mathrm{CODH})$ from Moorella thermoacetica and Acetobacterium woodii contains two Ni-FeS clusters. The 
formate dehydrogenase $(\mathrm{FDH})$ of $M$. thermoacetica that catalyzes the reduction of $\mathrm{CO}_{2}$ to formate is a tungsten, selenium and FeS cluster containing metalloenzyme ( Ragsdale and Pierce, 2008).

So far, most studies on the production of ethanol from $\mathrm{CO}$ have focused on how various macronutrients (e.g., nitrogen sources) and their concentrations affect the fermentation process. Hardly any research has focused on how trace metals influence ethanol production and none has studied their effects in bioreactors with continuous feed of the gaseous substrate. One study has been published but in batch assays and with no pH control (Saxena and Tanner, 2011). Since tungsten and selenium are components of formate dehydrogenase (FDH), whereas aldehyde:ferredoxin oxidoreductase (AFOR) that catalyzes reduction of carboxylic acids to aldehydes is a tungsten containing enzyme (Fig. 1) (Wang et al., 2013), the purpose of this study was to investigate the effects of tungsten and selenium on fermentation of CO by Clostridium autoethanogenum and on product distribution in batch and continuous gas-fed bioreactors. The effect of the presence of vitamins and the influence of $\mathrm{pH}$ were also investigated.

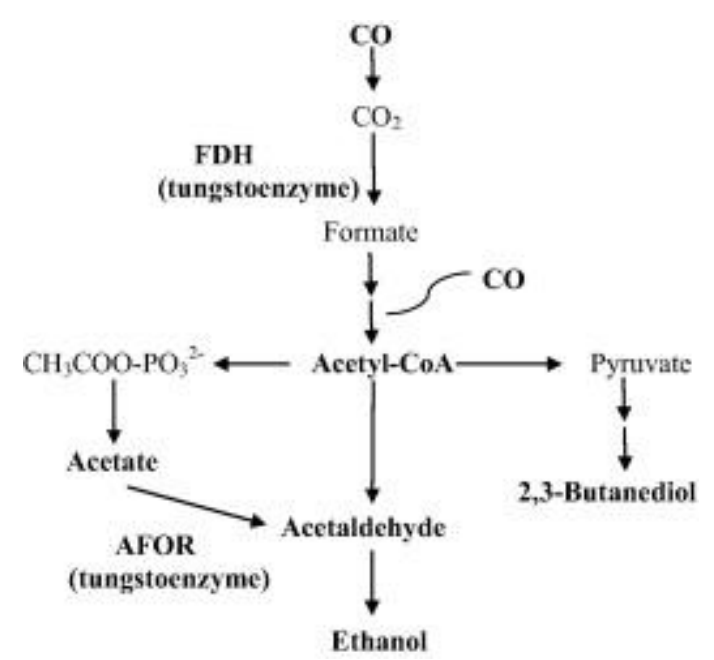

Fig. 1.

Wood-Ljungdahl pathway and metabolites formation from acetyl-CoA, with the corresponding metalloenzymes. Abbreviations:FDH, formate dehydrogenase; AFOR, aldehyde:ferredoxin oxidoreductase.

\section{Methods}

\subsection{Bottle batch experiments}

Batch experiments were conducted without $\mathrm{pH}$ control to study the effect of trace metals, tungsten (W), selenium (Se) as well as vitamins on growth and product formation in C. autoethanogenum DSM 10061. The growth medium to maintain the bacteria as well as the production medium used for the batch experiments is given in Table 1. Five independent tests were performed in duplicate with the production medium having different trace metal compositions, as mentioned hereafter, without vitamins: (1) trace metal SL-10 without W and Se [TM]; (2) SL-10 with $0.075 \mu \mathrm{M} \mathrm{W}$ (refers to the $\mathrm{W}$ concentration in the test vials) [Low W]; (3) SL-10 with $0.144 \mu \mathrm{M}$ Se [Low Se]; (4) SL-10 with $0.75 \mu \mathrm{M} \mathrm{W}$ [High W] and (5) SL-10 with $1.44 \mu \mathrm{M}$ Se [High Se]. Another set of four experiments was performed in duplicate to check the need and the effect of additional vitamins (Vit) on CO bioconversion: (1) SL-10 and Vit [Vit]; (2) SL-10 with $0.75 \mu \mathrm{M} \mathrm{W}$ and Vit [W-Vit]; (3) SL-10 with $1.44 \mu \mathrm{M}$ Se and Vit [Se-Vit]; (4) SL-10 with $0.75 \mu \mathrm{M} \mathrm{W}$ and 
$1.44 \mu \mathrm{M}$ Se as well as Vit [All]. $1 \mathrm{ml}$ of vitamin solution ( Table 1) per liter of production medium was used for the experiments with vitamins (Vit).

Table 1. Composition of culture media used in the experiments.

Growth medium ( $\mathrm{pH}$ 6)

Composition (per liter distilled water): $\mathrm{NH}_{4} \mathrm{Cl}, 0.9 \mathrm{~g} ; \mathrm{NaCl}, 0.9 \mathrm{~g} ; \mathrm{MgCl}_{2} \cdot 6 \mathrm{H}_{2} \mathrm{O}, 0.4 \mathrm{~g} ; \mathrm{KH}_{2} \mathrm{PO}_{4}$, $0.75 \mathrm{~g} ; \mathrm{K}_{2} \mathrm{HPO}_{4}, 1.5 \mathrm{~g} ; \mathrm{FeCl}_{3} \cdot 6 \mathrm{H}_{2} \mathrm{O}, 0.0025 \mathrm{~g}$; trypticase peptone, $2.0 \mathrm{~g}$; yeast extract, $1.0 \mathrm{~g}$; cysteine- $\mathrm{HCl}, 0.75 \mathrm{~g} ; 0.1 \%$ resazurin, $0.5 \mathrm{~mL}$; with $0.5 \%$ xylose and $\mathrm{SL}-10$ solution, $1.0 \mathrm{~mL}$. The trace metal stock solution SL-10 contained (per liter): $7.7 \mathrm{M} \mathrm{HCl}, 10 \mathrm{~mL} ; \mathrm{FeCl}_{2} \cdot 4 \mathrm{H}_{2} \mathrm{O}, 1.5 \mathrm{~g}$; $\mathrm{MnCl}_{2} \cdot 4 \mathrm{H}_{2} \mathrm{O}, 100 \mathrm{mg} ; \mathrm{H}_{2} \mathrm{BO}_{3}, 6 \mathrm{mg} ; \mathrm{CoCl}_{2} \cdot 2 \mathrm{H}_{2} \mathrm{O}, 190 \mathrm{mg} ; \mathrm{CuCl}_{2} \cdot 2 \mathrm{H}_{2} \mathrm{O}, 2 \mathrm{mg} ; \mathrm{NiCl}_{2} \cdot 6 \mathrm{H}_{2} \mathrm{O}$, $24 \mathrm{mg}$; and $\mathrm{Na}_{2} \mathrm{MoO}_{4} \cdot 2 \mathrm{H}_{2} \mathrm{O}, 36 \mathrm{mg}$

\section{Production medium ( $\mathrm{pH} 5.75$ )}

Composition (per liter distilled water): $\mathrm{NaCl}, 0.9 \mathrm{~g} ; \mathrm{MgCl}_{2} \cdot 6 \mathrm{H}_{2} \mathrm{O}, 0.4 \mathrm{~g} ; \mathrm{KH}_{2} \mathrm{PO}_{4}, 0.75 \mathrm{~g} ; \mathrm{K}_{2} \mathrm{HPO}_{4}$, $1.5 \mathrm{~g}$; yeast extract $0.5 \mathrm{~g} ; \mathrm{FeCl}_{3} \cdot 6 \mathrm{H}_{2} \mathrm{O}, 0.0025 \mathrm{~g} ; 0.1 \%$ resazurin, $0.5 \mathrm{~mL}$; cysteine- $\mathrm{HCl} 0.75 \mathrm{~g}$ and SL-10 solution, $1.0 \mathrm{~mL}$

\section{Vitamins}

The vitamin stock solution contained (per liter) $10 \mathrm{mg}$ each of para-aminobenzoic acid, calcium pantothenate, nicotinic acid, riboflavin, thiamine, a-lipoic acid, and vitamin B12, $4 \mathrm{mg}$ each of $\mathrm{d}$ biotin, folic acid and $20 \mathrm{mg}$ pyridoxine

\section{Tungsten and selenium}

The chemicals used were $\mathrm{Na}_{2} \mathrm{WO}_{4} \cdot 2 \mathrm{H}_{2} \mathrm{O}$ and $\mathrm{Na}_{2} \mathrm{SeO}_{3}$

Studies were carried out in duplicate at an initial pH of 5.75 in $100 \mathrm{ml}$ serum vials with $30 \mathrm{ml}$ production medium and inoculated with $2.5 \mathrm{ml}$ of actively growing seed culture, which was grown with $\mathrm{CO}$ as sole carbon source. The bottles were maintained under anaerobic conditions. They were pressurized to 1.2 bar with $100 \% \mathrm{CO}$ and were agitated at $150 \mathrm{rpm}$ inside an orbital incubator at $30{ }^{\circ} \mathrm{C}$. The experimental set-up and the method used for media preparation as well as sampling details are described elsewhere (Abubackar et al., 2011b).

\subsection{Continuous gas-fed bioreactor experiments with tungsten}

Two bioreactor experiments were carried out in a 2-L New Brunswick Scientific BIOFLO 110 bioreactor at either $\mathrm{pH} 6.0(\mathrm{High} \mathrm{pH})$ or $\mathrm{pH} 4.75(\mathrm{Low} \mathrm{pH})$ with $1.2 \mathrm{~L}$ batch liquid medium and $\mathrm{CO}(100 \%)$ as the gaseous substrate, continuously fed at a rate of $10 \mathrm{ml} / \mathrm{min}$ using a mass flow controller (Aalborg GFC 17). The medium composition used for the experiments was the same as in batch assays with the trace metal solution containing $0.75 \mu \mathrm{M} \mathrm{W}$, as this was shown to favor the desired bioconversion pathway in the batch assays. The bioreactor was maintained at a constant temperature of $30{ }^{\circ} \mathrm{C}$, with a constant agitation speed 
of $250 \mathrm{rpm}$ throughout the experiments. $10 \%$ of an actively growing culture, which was grown for $48 \mathrm{~h}$ with $\mathrm{CO}$ as sole carbon source, was used as the inoculum and was aseptically transferred to the bioreactor. The $\mathrm{pH}$ of the medium was automatically maintained at a constant value of either 6.0 or 4.75 , through the addition of a $2 \mathrm{M} \mathrm{NaOH}$ or a $2 \mathrm{M} \mathrm{HCl}$ solution, fed by means of a peristaltic pump. Gas samples of $0.2 \mathrm{~mL}$ were taken from the inlet and outlet sampling ports of the bioreactor to monitor the $\mathrm{CO}$ and $\mathrm{CO}_{2}$ concentrations. Similarly, $2 \mathrm{~mL}$ of liquid sample was periodically withdrawn from the reactor, once every $24 \mathrm{~h}$, in order to measure the optical density $\left(O D_{\lambda}=600 \mathrm{~nm}\right)$ and estimate the biomass concentration. Afterwards the sample was filtered with a syringe using a $0.22 \mu \mathrm{m}$ PTFE-filter before analyzing the concentrations of soluble products.

\subsection{Analytical equipment and measurement protocols}

Gas-phase CO concentrations were measured using an HP 6890 gas chromatograph (GC) equipped with a thermal conductivity detector (TCD). The GC was fitted with a $15 \mathrm{~m}$ HP-PLOT Molecular Sieve 5A column (ID: $0.53 \mathrm{~mm}$, film thickness: $50 \mu \mathrm{m}$ ). The oven temperature was initially kept constant at $50{ }^{\circ} \mathrm{C}$, for $5 \mathrm{~min}$, and then raised by $20^{\circ} \mathrm{C} \mathrm{min}^{-1}$ for $2 \mathrm{~min}$, to reach a final temperature of $90{ }^{\circ} \mathrm{C}$. The temperature of the injection port and the detector were maintained constant at $150^{\circ} \mathrm{C}$. Helium was used as the carrier gas. Similarly, $\mathrm{CO}_{2}$ was analyzed on an HP 5890 gas chromatograph, equipped with a TCD. The injection, oven and detection temperatures were maintained at 90,25 and $100{ }^{\circ} \mathrm{C}$, respectively. For 2,3 -butanediol identification, a Thermo Scientific ISQ ${ }^{\mathrm{TM}}$ single quadrupole GC-MS system, operated at $70 \mathrm{eV}$, mounted with a HP-5 ms column (30 m $\times 0.25 \mathrm{~mm} \times 0.25 \mu \mathrm{m}$ film thickness) was used. The water-soluble products, acetic acid, ethanol and 2,3-butanediol, in the culture broth were analyzed using an HPLC (HP1100, Agilent Co., USA) equipped with a $5 \mu \mathrm{m} \times 4 \mathrm{~mm} \times 250 \mathrm{~mm}$ Hypersil ODS column and a UV detector at a wavelength of $284 \mathrm{~nm}$. The mobile phase was a $0.1 \%$ ortho-phosphoric acid solution fed at a flow rate of $0.5 \mathrm{ml} / \mathrm{min}$. The column temperature was set at $30^{\circ} \mathrm{C}$. Cell mass was estimated by measuring the absorbance of the sample at a wavelength of $600 \mathrm{~nm}$ using a UV-visible spectrophotometer (Hitachi, Model U-200, Pacisa \& Giralt, Madrid, Spain). The measured absorbance was then compared to the previously generated calibration curve to calculate the corresponding biomass concentration $(\mathrm{mg} / \mathrm{L})$. Besides, the redox potential was monitored continuously using a $\mathrm{Ag} / \mathrm{AgCl}$ reference electrode maintained inside the bioreactor and connected to a transmitter (M300, Mettler Toledo, Inc. USA).

\section{Results and discussion}

\subsection{Bottle batch experiments}

Fig. 2 and Fig. 3 show the ethanol/acetic acid and butanediol/acetic acid ratio for the two sets of experiments. The experimental results show that the highest ethanol to acetic acid ratio obtained was 0.19 in the experiment designated as High W; that is $173 \%$ higher than the ratio obtained in the experiment with High Se. It is clear from the plot that the ethanol/acetic acid ratio, in batch tests, increased with the presence of tungsten in the medium. In the case of selenium, the ratio obtained was roughly similar in either the Low Se or the High Se experiment, with a value of 0.013 (Fig. 2a), which was even lower than in the control medium (TM). Hence it can be concluded that selenium did not allow to increase the ethanol/acetic acid ratio in $C$. autoethanogenum. It did not even favor considerably acetic acid production compared to the control medium. A recent report on a study with another bacterial strain in batch assays 
agrees with the present findings, and suggested no significant change in acetic acid production with or without selenium in the medium ( Saxena and Tanner, 2011).

(a)

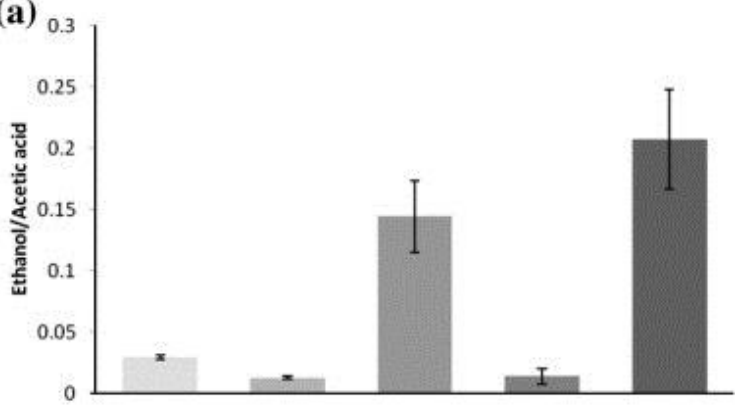

TM $=$ LowSe $=$ Low W $=$ HighSe $=$ HighW

(b)

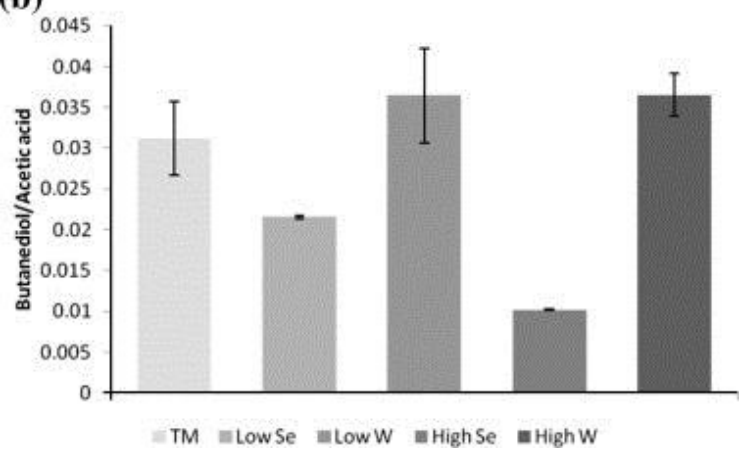

(a)

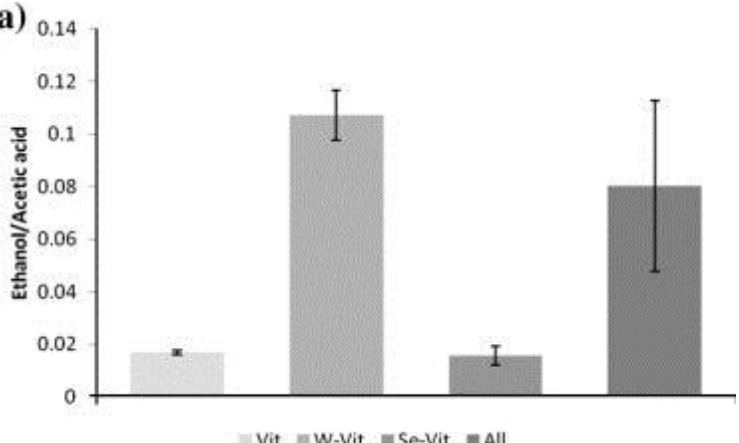

(b) 0

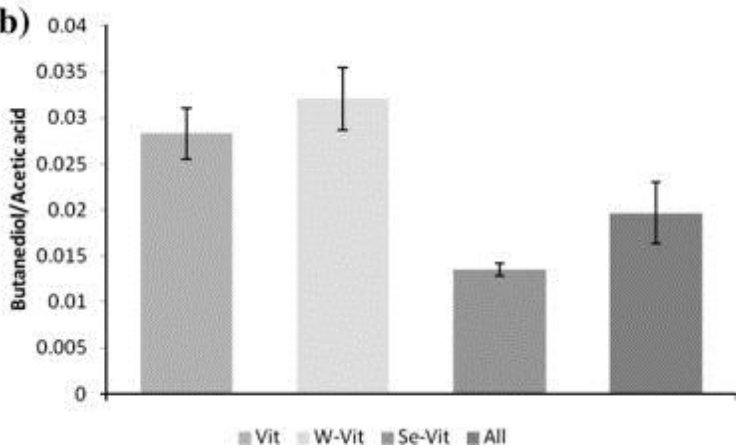

Fig. 2.

(a) Ethanol/acetic acid ratio and (b) Butanediol/acetic acid ratio, obtained in absence of vitamins. TM = trace metal solution without selenium and tungsten. The error bars represent the standard deviations.

Fig. 3.

(a) Ethanol/acetic acid and (b) Butanediol/acetic acid ratio, obtained in presence of vitamins. All = presence of selenium, tungsten in addition to vitamins. The error bars represent the standard deviations.

Some tungstoenzymes involved in the WL pathway and its subsequent routes that lead to metabolites production, include formate dehydrogenase (FDH) and aldehyde:ferredoxin-oxidoreductase (AFOR), having pterin cofactors as their active sites (Fig. 1). FDH catalyzes the first reaction in the WL pathway, 
that is the two-electron reduction of $\mathrm{CO}_{2}$ to formate (Ragsdale and Pierce, 2008). The first originally isolated tungstoenzyme is the FDH from Clostridium thermoaceticum. It contains 1 tungsten atom, 1 selenium, 18 iron and about 25 inorganic sulfur per dimeric unit, and utilizes NADPH as the physiological electron carrier (Yamamoto et al., 1983). It was reported that the presence of tungsten, selenium, molybdenum and ferrous ions in the growth medium stimulates FDH synthesis ( Yamamoto et al., 1983). Recently, it was reported that FDH in $C$. autoethanogenum forms complexes with an electron bifurcating hydrogenase enzyme that is NADP specific (Wang et al., 2013). The chemical analysis of this complex revealed that it contains tungsten. Experiments using Clostridium ragsdalei to study the effect of trace metals, when using $\mathrm{CO}$ as a substrate, indicated that the presence of tungsten $\left(\mathrm{WO}_{4}{ }^{-}\right)$at a concentration of $0.68 \mathrm{I} \mu \mathrm{M}$, yielded an ethanol production of $35.73 \mathrm{mM}$, which improved to $72.3 \mathrm{mM}$ upon increasing the tungsten concentration to $6.81 \mu \mathrm{M}$ (Saxena and Tanner, 2011). In that study, it was suggested that the presence of both selenium and tungsten in the medium decreases the activity of FDH in $C$. ragsdalei compared to media containing either tungsten or selenium only. AFOR, on the other hand, catalyzes the reduction of acetic acid to acetaldehyde. It was reported that AFOR from the hyperthermophilic archaeon Pyrococcus furiosus is a homodimer with $1 \mathrm{~W}$ and 4-5 Fe atoms per molecule ( Kletzin and Adams, 1996).

The results from the second set of experiments, aimed at studying the effect of adding a vitamin solution, showed that the presence of additional vitamins did not enhance the ethanol/acetic acid ratio. Interestingly, in the medium containing both selenium and vitamins, besides tungsten (“All”, Fig. 3a), the ethanol/acetic acid ratio was twenty-five percent lower than the value obtained in the medium containing both tungsten and vitamins but without any addition of selenium ("W-Vit", Fig. 3a). While many researchers add vitamins in studies on biofuels production (e.g., ethanol) with clostridia, the present data questions the need of such addition, which is a relevant cost-related issue. Our $C$. autoethanogenum strain did not need the supply of additional vitamins for ethanol production. To the best of our knowledge, this is different from otherClostridium strains described so far. One possible explanation is that this $C$. autoethanogenum strain has repeatedly been transferred to fresh media without adding vitamins and could therefore have adapted to such conditions. It may be assumed that, in the present study with $C$. autoethanogenum, selenium would inhibit the ethanol production pathway and partly counteract the favorable effect of tungsten. Trace metals might exhibit different effects in different CO-metabolizing strains, but tungsten showed a clear positive effect on ethanol production in our batch assays with $C$. autoethanogenum, while selenium at either no positive effect or even a negative effect depending on the nature of other elements (i.e., trace metals or vitamins) present in the medium.

The production of small amounts of 2,3-butanediol was also observed during $\mathrm{CO}$ fermentation in all the batch experiments. The maximum butanediol/acetic acid ratio obtained in the present work was 0.032 , and was exactly the same for all the experiments that contained tungsten, irrespective of the tungsten concentration and the presence or not of vitamins (Figs. 2b and 3b). Such data cannot be compared to any other previous experiment as no other study has focused on the effect of trace metals on 2,3-butanediol production from $\mathrm{CO}$ in Clostridia. From Fig. 2 and Fig. 3, it appears that the presence of tungsten increases the butanediol/acetic acid ratio similarly as in the case of the ethanol/acetic acid ratio. However, when compared to the control medium (TM) (with no tungsten nor selenium), the addition of tungsten increased more the ethanol/acetic acid ratio than the butanediol/acetic acid ratio. Indeed, the ethanol/acetic acid ratio was 5 to 7 times higher when adding tungsten (either at low or high W concentration), while the butanediol/acetic acid ratio increased by only about $20 \%$ when adding tungsten compared to TM. In any case, for both ethanol and 2,3-butanediol, it can be concluded that their relative 
concentration, compared to acetic acid, decreases under the following conditions, without the addition of a vitamin-solution: presence of tungsten (no selenium) > no tungsten nor selenium > presence of selenium (no tungsten). In the WL pathway and later in 2,3-butanediol production, acetyl-CoA with $\mathrm{CO}_{2}$ are converted to pyruvate using pyruvate:ferredoxin oxidoreductase (PFOR). Pyruvate gets reduced by acetolactate synthase and acetolactate decarboxylase to acetoin and then later to 2,3-butanediol using 2,3-butanediol dehydrogenase (23BDH) (Köpke et al., 2011). Köpke et al. (2014) recently discovered that $C$. autoethanogenum contains two dehydrogenases that are able to reduce acetoin to 2,3-butanediol, namely $23 \mathrm{BDH}$ and primary-secondary alcohol dehydrogenase.

The final pHs after these experimental batch runs were also measured. The production of acetic acid during the growth decreased the $\mathrm{pH}$ of the medium significantly and this usually inhibited the bacterial growth and metabolites production. The initial $\mathrm{pH}$ of the medium was 5.75 and the initial phosphate concentration was $14 \mathrm{mM}$. Phosphate in the form of $\mathrm{KH}_{2} \mathrm{PO}_{4} / \mathrm{K}_{2} \mathrm{HPO}_{4}$ was used as $\mathrm{pH}$-buffering solution. It was observed that the final $\mathrm{pH}$ value was in the range of $3.80-4.00$ for all the experiments.

The above findings in batch bottles confirm that the presence of tungsten improves the ethanol/acetic acid as well as the butanediol/acetic acid ratios, while the addition of selenium and vitamins had no favorable effect for ethanol production. Hence, in further studies in bioreactors with continuous CO supply, a trace metal solution with tungsten was used and vitamins and selenium were omitted, as described below. Since the $\mathrm{pH}$ value would affect biomass growth and the production of metabolites, the next experiment was performed using a $\mathrm{pH}$-control unit in order to maintain a constant $\mathrm{pH}$.

\subsection{Bioreactor experiment with continuous $\mathrm{CO}$ supply}

\subsubsection{Biomass profile}

Fig. 4 shows that the $\mathrm{pH}$ value had a profound effect on biomass production. Although $\mathrm{pH}$ could not be maintained constant in the batch bottle assays described above; in the present bioreactor studies $\mathrm{pH}$ remained stable throughout the experiments. To the best of our knowledge, no previous other study has been reported on the effect of trace metals and vitamins in continuous $\mathrm{CO}$-fed bioreactors under regulated, constant, $\mathrm{pH}$ conditions. $\mathrm{pH}$ control is important as it represents an additional parameter expected to affect biomass growth and production of metabolites. Biomass started growing instantly without any lag phase at $\mathrm{pH}$ 6.0, while, a $24 \mathrm{~h}$ lag phase was observed in the experiment at $\mathrm{pH} 4.75$ (Fig. 4). A maximum biomass concentration of $287.77 \mathrm{mg} / \mathrm{L}$ was achieved at $\mathrm{pH} 6.0$ which is $109 \%$ higher than the maximum value obtained at $\mathrm{pH} 4.75$ and, during the exponential phase, biomass was found to increase at a rate $70 \%$ faster at $\mathrm{pH} 6$ than at $\mathrm{pH} 4.75$. This can be attributed to the negative impact of $\mathrm{pH}$ deviations from the organism's optimum $\mathrm{pH}$ range for growth i.e., between $\mathrm{pH} 5.8$ and 6.0. Hence, the results demonstrated that the growth of $C$. autoethanogenum was limited when $\mathrm{pH}$ decreased sharply, under slightly acidic conditions. The biomass entered the stationary phase after $48 \mathrm{~h}$ and $96 \mathrm{~h}$, respectively, with the pHs set at either 4.75 or 6.0 . The amount biomass achieved during the experimental run is comparatively lower than that obtained for studies with other Clostridium strains ( Abubackar et al., 2011a and Mohammadi et al., 2011). In one of our previous studies in bioreactor with continuous $C O$ supply and with $1 \mathrm{~g} / \mathrm{L}$ yeast extract at $\mathrm{pH}$ 5.75, the maximum biomass obtained was $302.4 \mathrm{mg} / \mathrm{L}$, which is comparable to the maximum cell mass concentration obtained in this study at pH 6.0 (Abubackar et al., 2015). However, most batch 
studies with the strain $C$. autoethanogenum usually reported a low level of biomass growth compared to other bacterial species ( Cotter et al., 2009 and Guo et al., 2010). Cotter et al. (2009) reported a maximum biomass concentration of $150 \mathrm{mg} / \mathrm{L}$ in $C$. autoethanogenum, achieved while feeding syngas (20\% $\mathrm{CO})$ at a flow rate of $10 \mathrm{ml} / \mathrm{min}$.

(a)
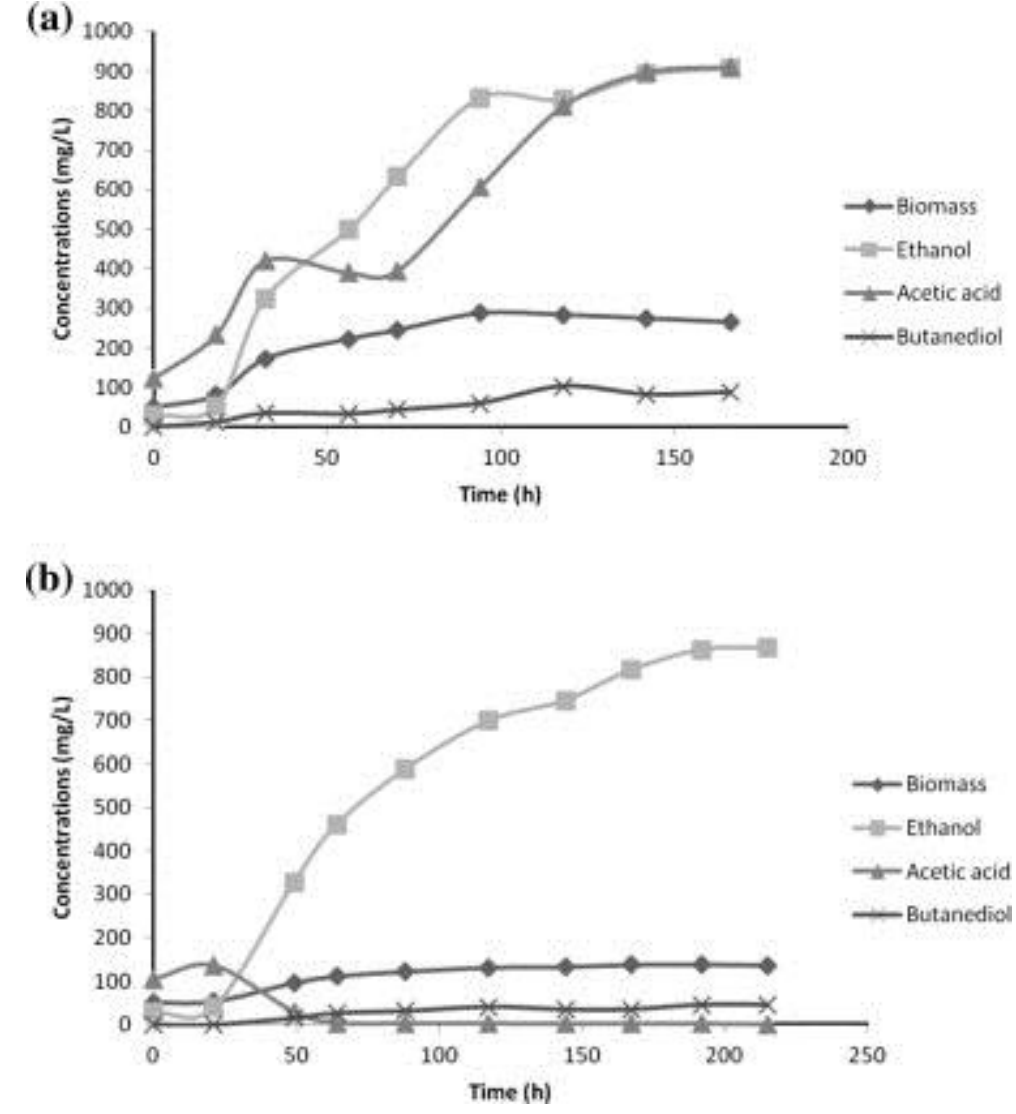

Fig. 4.

Cell mass and products profile at two different $\mathrm{pHs}$ studied in bioreactors: (a) pH 6 and (b) $\mathrm{pH}$ 4.75 .

The low cell mass concentration in bioreactor studies might be due to two reasons, either to limited nutritional availability in aqueous phase or/and to low availability of gaseous substrate. Biomass yields might also be a strain-linked parameter. Most of our own data, as well as some other published studies, suggest that biomass growth and consequently ethanol production from CO-related substrates seems to be generally lower in $C$. autoethanogenum than in strains such as Clostridium. ljungdahlii ( Abubackar et al., 2015, Guo et al., 2010 and Mohammadi et al., 2011). The solubility of CO in liquid phase is low as well as its mass transfer into the aqueous medium. Hence, in this state of limited mass transfer, the microorganism could not obtain sufficient substrate for growth and maintenance, which eventually leads to a low growth rate. Since vitamins did not show any effect on biomass accumulation in batch bottle experiments with this specific strain, it was eliminated in the bioreactor study, but to the best of our knowledge, the absence of vitamins would not be an explanation for the low biomass growth. However, a low medium cost is absolutely essential for optimizing the techno-economics of syngas fermentation. In a study using Alkalibaculum bacchi, a 50\% higher cell mass concentration was reported in YE medium along with vitamins and mineral solutions than with corn steep liquor (CSL) medium, though the maximum cell mass concentration obtained with YE was still only $330 \mathrm{mg} / \mathrm{L}$ ( Liu et al., 2014). 


\subsubsection{Product formation}

As can be observed from the figure (Fig. 4), the metabolic products obtained from CO fermentation were strongly affected by the $\mathrm{pH}$. In some of our previous studies, it was found that $C$. autoethanogenumproduced a higher amount of acetic acid than ethanol under the experimental conditions specifically used in that work ( Abubackar et al., 2015). In the present work, ethanol and acetic acid were the dominant final fermentation products in the study at $\mathrm{pH} 6.0$ with productions reaching a maximum of $907.72 \mathrm{mg} / \mathrm{L}$ and $910.69 \mathrm{mg} / \mathrm{L}$, respectively. A maximum ethanol concentration of $867 \mathrm{mg} / \mathrm{L}$ was produced at $\mathrm{pH} 4.75$, together with no acetic acid production and a negligible concentration $(<50 \mathrm{mg} / \mathrm{L})$ of butanediol as the alcohol byproduct. It can be suggested from this study that changing the $\mathrm{pH}$ of the medium at a specific stage of the continuous $\mathrm{CO}$ fermentation process induces a metabolic shift. In contrast, at $\mathrm{pH} 6.0$, concomitant, continuous, acetic acid and ethanol production was observed, and it could be noted that the ethanol to acetic acid ratio obtained was close to 1 . This value is greater than that obtained in our previous experimental studies without tungsten, where the maximum ethanol/acetic acid ratio obtained was 0.54 (Abubackar et al., 2015). Ethanol production is also higher than in the batch bottle assays described above with no $\mathrm{pH}$ regulation. A significant part of the $\mathrm{CO}$ fed was directed towards acetic acid production at the branch point of acetyl-CoA in the WL pathway ( Fig. 1). Even though ethanol started being produced at the early stage of the biomass growth at both $\mathrm{pHs}$, most of the ethanol titer was produced during the stationary phase. Although the final ethanol concentration was similar both at $\mathrm{pH} 4.75$ and $\mathrm{pH} 6.0$, it took about twice as long to reach such concentration at low $\mathrm{pH}$ than at high $\mathrm{pH}$. This is also related to the higher amount biomass found at high $\mathrm{pH}$.

As discovered from the bioreactor study, $\mathrm{CO}$ bioconversion by $C$. autoethanogenum changed from a predominant acetate and ethanol production at $\mathrm{pH} 6.0$ to predominant ("single") ethanol production at $\mathrm{pH}$ 4.75. An apparent metabolic shift of pathway from acidogenesis to solventogenesis upon decreasing the $\mathrm{pH}$ has also been observed previously in ABE (Acetone-Butanol-Ethanol) fermentation by $C$. acetobutylicum (Grupe and Gottschalk, 1992). Solventogenesis in syngas fermentation occurs during unfavorable growth conditions and in the presence of ample reducing equivalents. Using an initial low nutrient medium $\mathrm{pH}$ in order to improve the final ethanol titer decreases the cell mass concentration, which might then also decrease the productivity of metabolites. In order to overcome this, some researchers tried to use two stage bioreactors with operating conditions that support growth in the first bioreactor and with the second reactor with reduced $\mathrm{pH}$ and conditions that are favorable for ethanol production (Mohammadi et al., 2012 and Richter et al., 2013). Here, besides using two reactors in series, another alternative might consist in switching the $\mathrm{pH}$ from high (growth conditions) to low (solventogenesis conditions) values. During the fermentation at $\mathrm{pH} 4.75$, the production of acetic acid was not observed and furthermore, the acetic acid initially present in the inoculum was immediately consumed during the experiment. This happens, as discussed above, through the activity of the enzyme AFOR that converts acetic acid to acetaldehyde and latter to ethanol through an alcohol dehydrogenase (ADH) (Wang et al., 2013). Acetic acid production along with biomass growth and later partial acid conversion to ethanol was recently observed in some studies ( Liu et al., 2014). However, to the best of the authors knowledge, there is no previous study that reported carbon monoxide or syngas fermentation using wild type bacteria without any production or accumulation of acetic acid at all at the end of the fermentation process. 


\section{Conclusions}

In $C$. autoethanogenum, the addition of selenium and/or vitamins did no improve the ethanol/acetic acid ratio compared to a control medium without such additions. Furthermore, it clearly appears that the presence of tungsten improved ethanol production by $C$. autoethanogenum. Enhanced 2,3butanediol/acetic acid ratio was also obtained with the presence of tungsten, but not with selenium. Results from the bioreactor studies with continuous $\mathrm{CO}$ supply revealed that the presence of tungsten together with a shift from high $(\mathrm{pH} 6)$ to low $\mathrm{pH}(\mathrm{pH} 4.75)$ improves ethanol production by $C$. autoethanogenum without any accumulation of acetic acid.

\section{Acknowledgements}

The present research was financed through projects CTM2010-15796-TECNO and CTQ2013-45581-R from the Spanish Ministry of Science and Innovation and MINECO, respectively, and through European FEDER funds.

\section{References}

Abubackar et al., 2011a

H.N. Abubackar, M.C. Veiga, C. Kennes

Biological conversion of carbon monoxide: rich syngas or waste gases to bioethanol

Biofuels Bioprod. Biorefin., 5 (2011), pp. 93-114

Abubackar et al., 2011b

Abubackar, H.N., Veiga, M.C., Kennes, C., 2011b, Bioconversion of carbon monoxide to bioethanol: an optimization study. In: Kennes, C., Rene, E.R., Veiga, M.C. (Eds.), Biotechniques for Air Pollution Control and Bioenergy, vol. IV, La Coruña, pp. 347-351.

Abubackar et al., 2012

H.N. Abubackar, M.C. Veiga, C. Kennes

Biological conversion of carbon monoxide to ethanol: effect of $\mathrm{pH}$, gas pressure, reducing agent and yeast extract

Bioresour. Technol., 114 (2012), pp. 518-522

Abubackar et al., 2015

H.N. Abubackar, M.C. Veiga, C. Kennes

Ethanol and acetic acid production from carbon monoxide in a Clostridium strain in batch and continuous gas-fed bioreactors

Int. J. Environ. Res. Public Health, 12 (2015), pp. 1029-1043

Balat and Balat, 2009

M. Balat, H. Balat

Recent trends in global production and utilization of bioethanol fuel

Appl. Energy, 86 (2009), pp. 2273-2282

Bengelsdorf et al., 2013

F.R. Bengelsdorf, M. Straub, P. Dürre

Bacterial synthesis gas (syngas) fermentation

Environ. Technol., 34 (2013), pp. 1639-1651

Cotter et al., 2009

J.L. Cotter, M.S. Chinn, A.M. Grunden 
Influence of process parameters on growth of Clostridium ljungdahlii and Clostridium autoethanogenum on synthesis gas

Enzyme Microb. Technol., 44 (2009), pp. 281-288

Flach et al., 2013

Flach, B., Bendz, K., Krautgartner, R., Lieberz, S., 2013. EU Biofuels Annual 2013. GAIN. Report No: NL3034.

Grupe and Gottschalk, 1992

H. Grupe, G. Gottschalk

Physiological events in Clostridium acetobutylicum during the shift from acidogenesis to solventogenesis in continuous culture and presentation of a model for shift induction

Appl. Environ. Microbiol., 58 (1992), pp. 3896-3902

Guo et al., 2010

Y. Guo, J. Xu, Y. Zhang, H. Xu, Z. Yuan, D. Li

Medium optimization for ethanol production with Clostridium autoethanogenum with carbon monoxide as sole carbon source

Bioresour. Technol., 101 (2010), pp. 8784-8789

Kletzin and Adams, 1996

A. Kletzin, M.W.W. Adams

Tungsten in biological systems

FEMS Microbiol. Rev., 18 (1996), pp. 5-63

Köpke et al., 2011

M. Köpke, C. Mihalcea, F. Liew, J.H. Tizard, M.S. Ali, J.J. Conolly, B. Al-Sinawi, S.D. Simpson

2,3-Butanediol production by acetogenic bacteria, an alternative route to chemical synthesis, using industrial waste gas

Appl. Environ. Microbiol., 77 (2011), pp. 5467-5475

Köpke et al., 2014

M. Köpke, M.L. Gerth, D.J. Maddock, A.P. Mueller, F.-M. Liew, S.D. Simpson, W.M. Patrick

Reconstruction of an acetogenic 2,3-butanediol pathway involving a novel NADPH-dependent primary-secondary alcohol dehydrogenase

Appl. Environ. Microbiol., 80 (2014), pp. 3394-3403

Kundiyana et al., 2011

D.K. Kundiyana, R.L. Huhnke, M.R. Wilkins

Effect of nutrient limitation and two-stage continuous fermentor design on productivities during “Clostridium ragsdalei" syngas fermentation

Bioresour. Technol., 102 (2011), pp. 6058-6064

Latif et al., 2014

H. Latif, A.A. Zeidan, A.T. Nielsen, K. Zengler

Trash to treasure: production of biofuels and commodity chemicals via syngas fermenting microorganisms

Curr. Opin. Biotechnol., 27 (2014), pp. 79-87

Liu et al., 2014

K. Liu, H.K. Atiyeh, B.S. Stevenson, R.S. Tanner, M.R. Wilkins, R.L. Huhnke

Continuous syngas fermentation for the production of ethanol, $n$-propanol and $n$-butanol

Bioresour. Technol., 151 (2014), pp. 69-77

Mohammadi et al., 2011

M. Mohammadi, G.D. Najafpour, H. Younesi, P. Lahijani, M.H. Uzir, A.R. Mohamed

Bioconversion of synthesis gas to second generation biofuels: a review

Renew. Sustain. Energy Rev., 15 (2011), pp. 4255-4273 
Mohammadi et al., 2012

M. Mohammadi, H. Younesi, G.D. Najafpour, A.R. Mohamed

Sustainable ethanol fermentation from synthesis gas by Clostridium ljungdahlii in a continuous stirred tank bioreactor

J. Chem. Technol. Biotechnol., 87 (2012), pp. 837-843

Ragsdale and Pierce, 2008

S.W. Ragsdale, E. Pierce

Acetogenesis and the Wood-Ljungdahl pathway of $\mathrm{CO}_{2}$ fixation

BBA Proteins Proteomics, 1784 (2008), pp. 1873-1898

Richter et al., 2013

H. Richter, M. Martin, L. Angenent

A two-stage continuous fermentation system for conversion of syngas into ethanol

Energies, 6 (2013), pp. 3987-4000

Saxena and Tanner, 2011

J. Saxena, R.S. Tanner

Effect of trace metals on ethanol production from synthesis gas by the ethanologenic acetogen, Clostridium ragsdalei

J. Ind. Microbiol. Biotechnol., 38 (2011), pp. 513-521

Ueki et al., 2014

T. Ueki, K.P. Nevin, T.L. Woodard, D.R. Lovley

Converting carbon dioxide to butyrate with an engineered strain of Clostridium Ijungdahlii

MBio, 5 (5) (2014)

van Groenestijn et al., 2013

J.W. van Groenestijn, H.N. Abubackar, M.C. Veiga, C. Kennes

Bioethanol

C. Kennes, M.C. Veiga (Eds.), Air Pollution Prevention and Control: Bioreactors and Bioenergy, John Wiley \& Sons, Ltd, Chichester, UK (2013), pp. 431-463

Wang et al., 2013

S. Wang, H. Huang, J. Kahnt, A.P. Mueller, M. Köpke, R.K. Thauer

NADP-specific electron-bifurcating [FeFe]-hydrogenase in a functional complex with formate dehydrogenase in Clostridium autoethanogenum grown on $\mathrm{CO}$

J. Bacteriol., 195 (2013), pp. 4373-4386

Xie et al., 2015

B.-T. Xie, Z.-Y. Liu, L. Tian, F.-L. Li, X.-H. Chen

Physiological response of Clostridium Ijungdahlii DSM 13528 of ethanol production under different fermentation conditions

Bioresour. Technol., 177 (2015), pp. 302-307

Yamamoto et al., 1983

I. Yamamoto, T. Saiki, S.-M. Liu, L.G. Ljungdahl

Purification and properties of NADP-dependent formate dehydrogenase from Clostridium thermoaceticum, a tungsten-selenium-iron protein

J. Biol. Chem., 258 (1983), pp. 1826-1832 